\title{
Measurement methods on pastures and their use in environmental life-cycle assessment
}

\author{
MAGDALENA OHM ${ }^{1}$, MAXIMILIAN SCHÜLER ${ }^{1}$, SYLVIA WARNECKE ${ }^{1}$, \\ HANS MARTEN PAULSEN ${ }^{1}$, GEROLd RAHMANN ${ }^{1}$
}

Key words: grazing intake, dairy, global warming potential

\begin{abstract}
Measurements of the variable feed offer at pasture plots with a rising plate meter provide a data basis to improve grazing and pasture management. Calculating grazing intake by the use of regrowth values of biomass of temporally ungrazed pastures might be a practical and fast alternative to measurements with exclosure cages. On the explored pasture plots high differences in the dry matter intake of the cows were found. Optimizing pasture yields, e. g. by sward improvements and grazing management, offers chances to reduce environmental burdens of milk production. Every $\mathrm{kg}$ DM grass silage that is substituted by grazing intake reduces the global warming potential of milk production. Site specific potential was $1.5 \%$ per $\mathrm{kg}$ ECM from calculations with a complete farm model. Further reductions by improving feeding management and food quality are anticipated.
\end{abstract}

\section{Introduction}

A total of $70 \%$ of the world's agricultural area is covered by grassland (FAO 2008). It is an important and energy extensive feed source for livestock and good pasture management is required to maintain its productivity. Due to the selective grazing behavior of dairy cows and site and management related sward variability it is difficult to estimate pasture yield or pasture intake. A proper estimation of feed intake of animals on grassland enables the farmer to appropriately manage his pastures. This paper presents a fast and easy-to-use method to estimate pasture intake without exclosure cages. These data are used to describe material flows from grassland. Subsequently environmental impacts of an improved grazing management based on the whole farm process are calculated with the flow model FARM that is designed to conduct life-cycle assessments (LCA) of farm products.

\section{Material and methods}

Data were collected on the experimental station of the Thünen-Institute of Organic Farming, Trenthorst in Northern Germany (5346' N, 10³0' E; 10-43 m asl). For the dairy branch of the station an area of 37 hectare is used as permanent grassland for grazing, silage making and hay cutting. The farm converted from conventional to organic farming in 2001. Mean annual precipitation is $706 \mathrm{~mm}$ and mean annual temperature is $8.8^{\circ} \mathrm{C}$ (1978-2007). In 2012 precipitation was as low as $534 \mathrm{~mm}$, which is $34 \%$ lower than average. The soils of the permanent grassland are characterized as Cambisols and Luvisols. On the grassland, a mixture of grass, legumes (mostly Trifolium repens) and herbaceous plants is growing in different proportions. In 2012 the dairy cows (Black Holstein and Red Holstein double usage) grazed approximately 7 hours a day from 24th of April until 7th of October. The permanent grassland is divided into 13 plots (mean size 2.66 ha) and managed by rotational grazing with a duration of 2-10 days per plot. To estimate the pasture intake on a dry matter basis following formula (1) is used: (biomass before grazing - biomass after grazing) + (daily growth rate $x$ days of grazing). The biomass before and after grazing is measured at four representative GPS-located points per pasture plot (Fig. 1, left). The biomass was determined directly by cutting $0.5 \mathrm{~m} \times 1$ $\mathrm{m}$ to $1 \mathrm{~cm}$ above ground level, which took around 20 minutes per plot. The dry matter yield was determined by drying the biomass $\left(24 \mathrm{~h}, 60^{\circ} \mathrm{C}\right)$

\footnotetext{
${ }^{1}$ Thuenen-Institute of Organic Farming, Germany, www.ti.bund.de, magdalena.ohm@ti.bund.de
} 


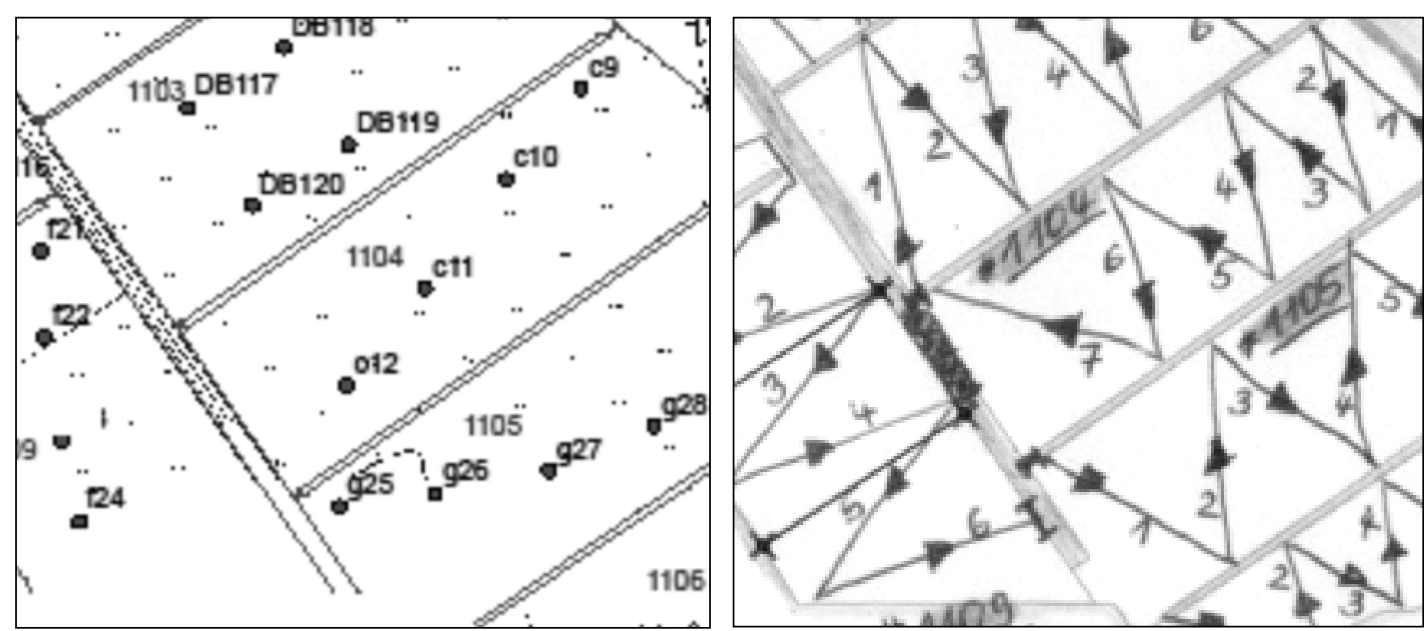

Figure 1. GPS-located sample points (left) were used to measure the difference before and after grazing and weekly zigzag measurement (right) were used to estimate the daily growth rates.

The daily growth rate was calculated on basis of weekly measurements at all ungrazed plots with a rising plate meter (FARMWORKS). It measures the compressed height of the pasture: the plate of the meter lowers from top to bottom until enough plant material carries the plate's weight. The rising plate meter was calibrated to the farm conditions of the permanent grassland in Trenthorst. The calibration shows a linear relationship between dry matter yield $(\mathrm{DM})$ and compressed sward height $(\mathrm{H})$ with the function: $\mathrm{DM}=100.41$ $\mathrm{x} \mathrm{H}+1(\mathrm{r} 2=0.75, \mathrm{n}=396)$. This function was used to calculate the dry matter yield by the sward height measurements. The sward height was measured every 10 steps (Fig. 1, right) while the plots were crossed in zigzag and needed around 12 minutes. For every crossing line the mean height was recorded. Both methods (four points cutting and zigzag measurement with rising plate meter) showed similar results when yield estimation per plot was compared (data not displayed).The LCA-FARM-Model was developed to calculate the environmental performance of milk production (Schüler and Paulsen, 2012). The input data were obtained from the real farming conditions on the experimental station. The parameters used are tillage steps, crop yields, manure amount, herd size, milk yields, feed intake and feeding regime which includes the grazing management. Greenhouse gas emissions were calculated according to the rules specified in IPPC (2006) and Rösemann et al. (2011). The global warming potential (GWP) connected with grass silage production at Trenthorst depends on the total yield (Table 1). In 2011 grass silage yield was very low (17.5 $\mathrm{t}$ ha-1) and the GWP was $327.6 \mathrm{~g} \mathrm{CO} 2$ eq. kg-1 DM. Yields around $26.5 \mathrm{t}$ ha-1 (mean of the years 2005, $2008,2009)$ are more representative for the location and had a GWP of $293.9 \mathrm{~g} \mathrm{CO} 2 \mathrm{eq} . \mathrm{kg}-1 \mathrm{DM}$. For following calculations a value of $300 \mathrm{~g} \mathrm{CO} 2 \mathrm{eq} . \mathrm{kg}-1$ DM grass silage is assumed.

Table 1. Global warming potential (100 a) of grass silage for yields of $17.5 \mathrm{t}$ ha-1 and $26.5 \mathrm{t}$ ha-1 in $\mathrm{g}$ CO2 eq. kg-1 DM (experimental farm Trenthorst, 2011 and mean of the years 2005, 2008 and 2009).

\begin{tabular}{|c|c|c|}
\hline Emission source & 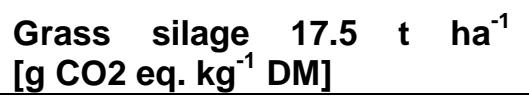 & $\begin{array}{l}\text { Grass silage } 26.5 \mathrm{t} \mathrm{ha}^{-1} \\
\text { [g CO2 eq. kg-1 DM] }\end{array}$ \\
\hline Supply-chain* & 11.8 & 8.8 \\
\hline $\begin{array}{l}\text { Transports of silage film, lime and } \\
\text { fuel to farm }\end{array}$ & 0.3 & 0.2 \\
\hline Fuel combustion from fieldwork & 89.4 & 66.4 \\
\hline Direct emissions from soil & 226 & 218.5 \\
\hline Combustion of silage film & $5.96 * 10^{-6}$ & $5.9 * 10^{-6}$ \\
\hline Sum & 327.6 & 293.9 \\
\hline
\end{tabular}

*The environmental burden of all upstream products have been calculated with datasets from the ecoinvent v2.2 database 


\section{Results and discussion}

For calculating grazing intake the biomass difference before and after grazing was added to the daily growth rate. The daily growth varied widely during the grazing season. The maximum was in spring with more than $70 \mathrm{~kg}$ dry matter (DM) per ha (Fig. 2). The mean daily growth rate was around $25 \mathrm{~kg}$ DM per ha. It also shows some negative values which can be attributed to dry periods when the grass went limp.

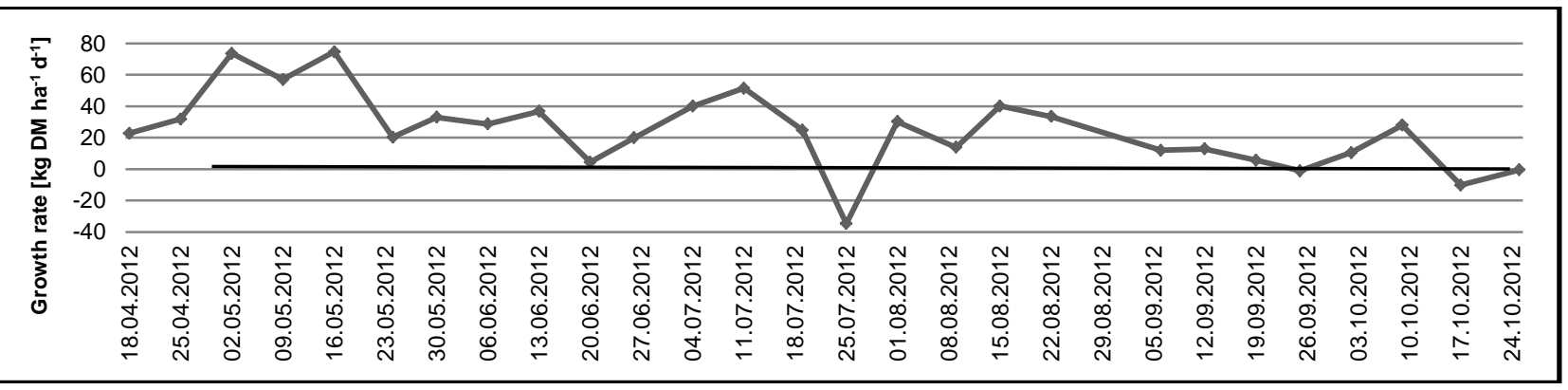

Figure 2. Daily growth rate of dry matter on ungrazed plots in 2012.

Both the dry matter yields from direct cuttings and the estimated yield from growth rates (formula 1) show variations between the plots (Fig. 3). The sum is basis to calculate the DM intake per cow and plot. This is the parameter for the LCA.

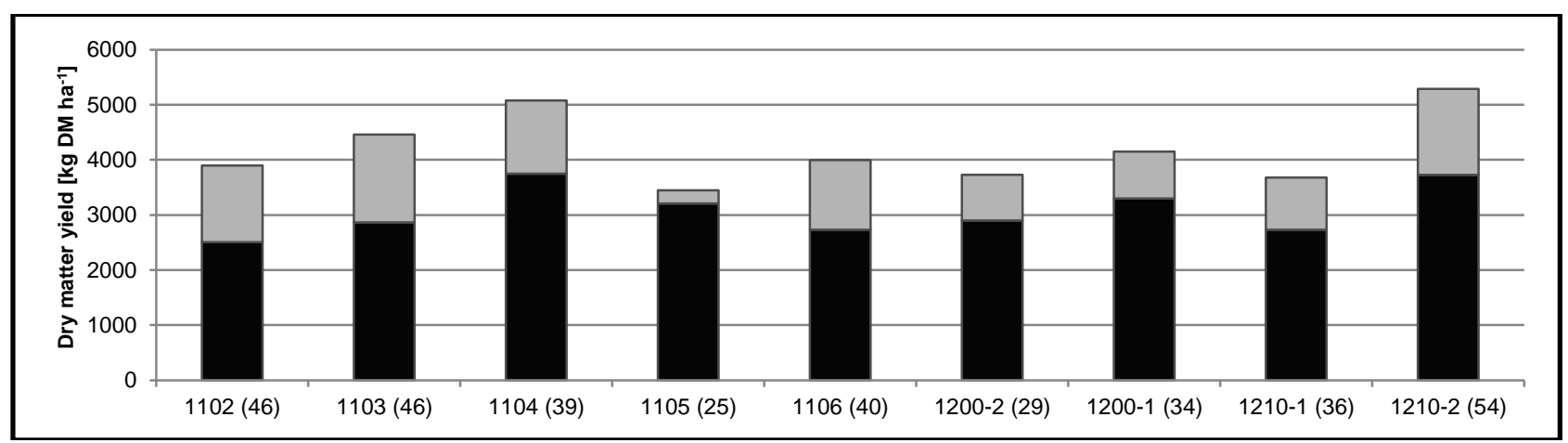

Figure 3. Dry matter yields of the grazed pasture plots calculated by the difference before and after grazing (black) and daily growth rate (grey) in 2012. In brackets: Number of grazing days.

In detail the dry matter intake per cow and day was calculated by the dry matter yield per plot, number of animals and days of grazing (Fig. 4). High differences between the plots occurred and might be an indicator for improvement. Differences might be caused by sward composition, season and soil site differences. But also improper grazing management decisions can lead to a low dry matter intake per cow. If improved management decisions could increase the dry matter intake of the dairy cows during grazing by $1 \mathrm{~kg}$ dry matter per day, equivalently less grass silage would be needed to be fed to get the same amount of milk yield. Substituting grass silage by improving grazing management reduces GWP per kg energy-corrected milk (ECM). In other words: This is the potential of an improved grazing management to reduce the GWP of milk. Calculating the LCA for the experimental station results in (a) GWP of $300 \mathrm{~g} \mathrm{CO} 2$ eq. per $\mathrm{kg}$ grass silage DM (Tab.1) and (b) $1 \mathrm{~kg} \mathrm{CO} 2$ eq. per $\mathrm{kg}$ ECM. At daily milk yields of $20 \mathrm{~kg} \mathrm{ECM} \mathrm{per} \mathrm{cow} \mathrm{and} \mathrm{day} \mathrm{the}$ GWP can be reduced by $15 \mathrm{~g}$ per $\mathrm{kg}$ ECM (=1.5\%) by substituting $1 \mathrm{~kg}$ DM grass silage by $1 \mathrm{~kg}$ DM intake from pasture. At the pasture plot with the lowest DM intake (plot 1102, Fig. 4) the GWP could even be reduced by $8.2 \%$ if daily DM intake during the grazing period could be more than doubled from 4.6 to $10 \mathrm{~kg}$. 


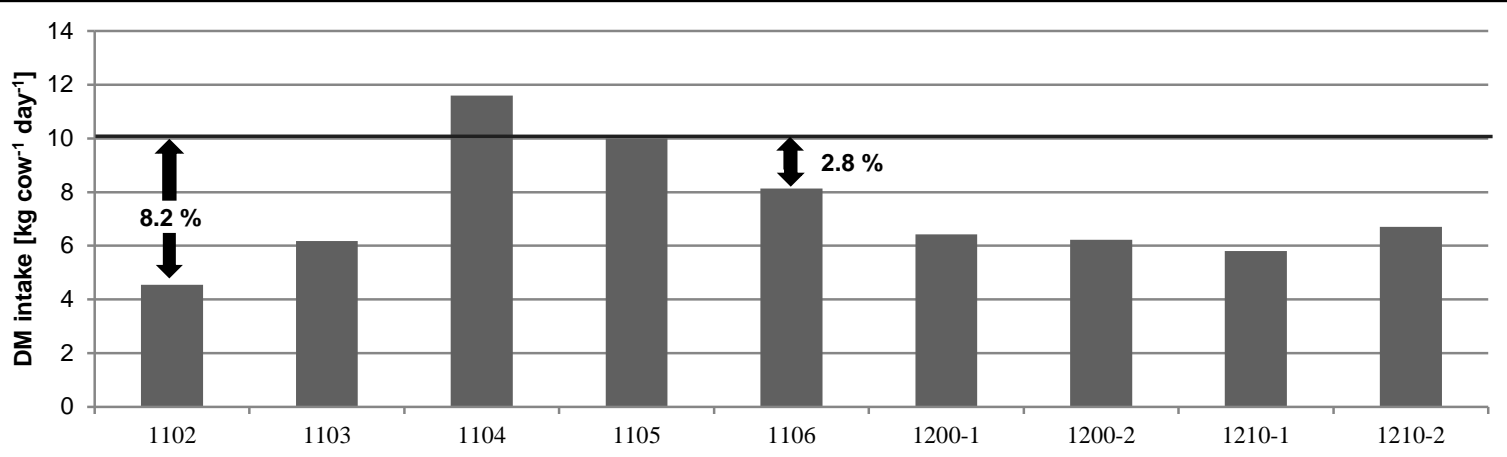

Figure 4. Daily dry matter (DM) intake per cow at the pasture plots in 2012. The \% shows the reduction potential of global warming per $\mathrm{kg} \mathrm{ECM} \mathrm{[ \% ]} \mathrm{by} \mathrm{increasing} \mathrm{the} \mathrm{DM} \mathrm{intake} \mathrm{by} \mathrm{grazing} \mathrm{to} 10$ kg cow-1 d-1.

\section{References}

FAO (2008): http://www.fao.org/ag/agp/agpc/doc/grass_stats/grass-stats.htm (26.9.2013)

IPCC (2006): IPCC Guidelines for National Greenhouse Gas Inventories, Prepared by the National Greenhouse Gas Inventories Programme. IGES, Japan

Rösemann C, Haenel H-D, Poddey E, Dämmgen U, Döhler H, Eurich-Menden B, Laubach P, Dieterle M, Osterburg B (2011): Calculations of gaseous and particulate emissions from German agriculture 1990-2009. Landbauforsch vTI AG 342, 402p

Schüler M, Paulsen HM (2012) An LCA based comparison of two different dairy breeds in an organic farm. 2nd Organic Animal Husbandry Conference Hamburg, Trenthorst, 12-14 September, 2012 